\title{
Timing of coronary artery bypass grafting after acute myocardial infarction: does it influence outcomes?
}

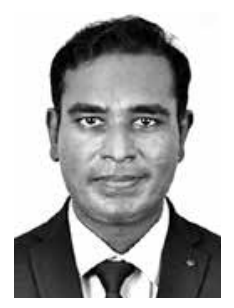

\author{
Anton Prem Thilak, Devika Thacker, Sufina Shales, Debasis Das, Sukanta Kumar Behera, \\ Arup Kumar Ghosh, Pradeep Narayan
}

Department of Cardiac Surgery, NH Rabindranath Tagore International Institute of Cardiac Sciences, Kolkata, India

Kardiochir Torakochir Pol 2021; 18 (1): 27-32

\begin{abstract}
Introduction: The optimal timing of coronary artery bypass grafting (CABG) operations in patients with recent acute myocardial infarction (AMI) remains unclear.

Aim: To assess the influence of timing on post-operative outcomes in patients undergoing CABG following AMI.

Material and methods: In this retrospective analysis 12,224 consecutive patients undergoing CABG were included. 2477 (20.5\%) patients had a history of AMI. Based on timing, patients were divided into 3 groups: those operated within 7 days of AMI; those operated after 7 days but within 1 month; and a third group operated after 1 month but within 3 months. The 3 groups were compared in terms of baseline, intra-operative, and post-operative morbidity and mortality. Multivariate analysis was carried out to assess the independent influence of timing of CABG on outcomes.

Results: There was no difference in terms of previous neurological events $(p=0.554)$, presence of carotid artery disease ( $p=0.555)$, prevalence of hypertension $(p=0.119)$, diabetes $(p=0.144)$, hypothyroidism $(p=0.53)$, chronic obstructive pulmonary disease $(p=0.079)$, peripheral vascular disease $(p=0.771)$, and impaired left ventricular function $(p=0.072)$. On univariate analysis, mortality risk was highest between 1 week and 1 month $(p=0.003)$. Multivariate analysis showed that the closer the $\mathrm{MI}$ and CABG duration, the higher the mortality (co-efficient $-0.517 ; p=0.019$; odds ratio $=0.596 ; 95 \% \mathrm{Cl}: 0.388-0.917$ ).

Conclusions: The duration between $\mathrm{MI}$ and CABG has a direct influence on outcomes after CABG. While it is clear that the longer the duration between $\mathrm{MI}$ and $\mathrm{CABG}$, the lower the mortality risk, it is however difficult to decide on an exact cut-off time frame.
\end{abstract}

Key words: coronary artery bypass grafting, myocardial infarction, timing.

\section{Introduction}

The mortality of coronary artery bypass grafting (CABG) following myocardial infarction is generally higher than in CABG in patients without myocardial infarction, and it has been shown to be influenced by a number of factors [1]. Significant controversy exists with regards to the influence of timing on outcomes. Some authors have considered timing of surgery to be the single most important determinant of outcome [2], and others suggest that time by itself is an unreliable criterion to decide on surgical revascularization [3].

This lack of consensus is perhaps due to the fact that there are important issues that influence outcome both when CABG is carried out early and when it is delayed. Early CABG involves operating on a more unstable patient, usually with left ventricular dysfunction, conduction abnormalities, and arrhythmias, and does not provide sufficient time to stop any anti-platelet agents or control any metabolic derangements. Moreover, myocardial oedema and the presence of a systemic inflammatory state further add to the risk of adverse outcome following early CABG. On the other hand, a delayed approach exposes the patient to risk of further ischaemic insults $[4,5]$. Also, it has been shown that a delayed approach has a significant impact on resource utilization [6]. As a result, efforts have been made to establish the ideal time to operate on these patients. However, this had led to conflicting results.

Some studies have advocated that a delayed approach significantly reduces the risk of mortality in these patients. It has also been shown that CABG carried out early in the presence of non-ST elevation myocardial infarction (NSTEMI) is associated with a significant increase in mortality [2]. Others have suggested that while there is no difference in mortality, there is a significant increase in inotropic and intra-aortic balloon pump (IABP) requirement in patients undergoing CABG after transmural or non-transmural MI [7]. At the same time, there is also evidence to suggest that delaying CABG might increase resource utilization without improving outcomes [6].

Address for correspondence: Pradeep Narayan, Department of Cardiac Surgery, NH Rabindranath Tagore International Institute of Cardiac Sciences, Kolkata, India, phone: +91 8017249115, e-mail: pradeepdoc@gmail.com

Received: 10.11.2020, accepted: 6.01.2021. 
There is also no consensus on an ideal cut-off time point that reliably determines the outcome in these patients. The California discharge data in patients undergoing coronary artery bypass grafting following acute myocardial infarction reported that those undergoing coronary artery bypass grafting 3 or more days after acute myocardial infarction had significantly lower mortality [8]. Other studies have shown that CABG within 7 days of acute myocardial infarction was the most important predictor of mortality [9]. Equally, comparison of emergent CABG within 24 hours with those in which CABG is performed after 3 days have shown no difference in outcomes [10].

\section{Aim}

The optimal timing of CABG operations in patients with recent acute myocardial infarction (AMI) remains unclear. In this study, we aim to assess the influence of timing on post-operative outcomes in patients undergoing CABG following AMI and explore the idea of an ideal cut-off point for carrying out $C A B G$ in these patients.

\section{Material and methods}

Patients undergoing primary, isolated, elective coronary artery bypass grafting after acute myocardial infarction at a single tertiary care centre over a 9-year period were included in the study. This was a retrospective study on prospectively collected data. Ethical approval was obtained from the Institutional Ethics Committee.

The exclusion criteria included patients with a history of concomitant valvular involvement. Previous percutaneous coronary intervention ( $\mathrm{PCl}$ ) was not an exclusion criteria.

Patients were divided into 3 groups based on time from infarct to coronary artery bypass grafting. The 3 timeframes were $0-7$ days, $>7$ days to 1 month, and $>1$ month but $<3$ months.

Comparison of the 3 groups was done in terms of baseline characteristics, operative details, and post-operative outcomes. Using timing of surgery as an independent variable, adjusted odds ratios for adverse outcomes were calculated.

\section{Definitions}

Myocardial infarction included both ST elevation MI and non-ST elevation MI, and thus was defined by the presence of angina with electrocardiographic (ECG) ST-segment elevation or depression with positive biomarkers of myocardial necrosis. The biomarker at our institution during the period of study was troponin I (Tnl). While data was collected on the $\mathrm{Tnl}$ values to define Ml; the duration between these measurements and CABG varied widely. We therefore used them to define MI but did not include the values in our analysis.

Definitions used in our study with regards to diabetes, chronic obstructive pulmonary disease (COPD), left ventricular dysfunction, deep sternal wound infection (DSWI), and respiratory and gastro-intestinal (GI) complications were as defined by the Society of Thoracic Surgeons (STS). Postoperative renal failure was graded according to the KDIGO criteria, but only stage III (increase of serum creatinine to $\geq 4.0 \mathrm{mg} / \mathrm{dl}$ or a 3-fold rise over the most recent preoperative creatinine level or a new requirement for dialysis) was taken as significant for the purpose of this study. Neurological complications included both cerebro-vascular accident (CVA) and transient ischaemic attack (TIA).

\section{Surgical techniques}

The strategy of revascularization was predominantly offpump (OPCAB) and in a small proportion on-pump beating heart surgery was used either on an elective basis or converted due to haemodynamic compromise. LIMA was harvested as a pedicle graft in almost all the cases. There was a general consensus regarding positioning and stabilization techniques during OPCAB, and we used both Octopus (Octopus 3; Medtronic, Minneapolis, MN, USA) and Starfish apical suction devices (Medtronic, Minneapolis, MN, USA) for stabilization along with an intra-coronary shunt (ClearView Intracoronary Shunt, Medtronic, Minneapolis, MN, USA).

\section{Anaesthetic techniques}

A standard anaesthetic technique was used throughout. Intraoperative trans-oesophageal echocardiography was used in the event of any haemodynamic instability to assess regional wall motion abnormality. Patients were extubated as soon as they met the institutional extubation criteria.

\section{Statistical analysis}

All continuous variables were expressed as mean \pm standard deviation and compared across the 3 groups. All categorical variables were expressed as numbers and percentages. Bivariate comparison was carried out across the 3 groups. Univariate logistic regression was done to identify predictors of adverse outcomes. Multivariate analysis was carried out to assess the independent effect of time on outcome. A multivariate model was created using variables that returned significance on univariate analysis along with clinically relevant factors known to have an influence on post-operative outcomes. Thus, the complete model included COPD, gender, body mass index, EuroSCORE, pre-operative haematocrit, history of smoking, left main coronary artery disease, usage of OPCAB, and emergency surgery. The effect size was reported as the odds ratio (OR) and its 95\% confidence interval (CI). All statistical tests were evaluated using a 2-tailed 0.05 level of significance. The data were analysed with SPSS version 22.

\section{Results}

During the study period (9 years) 12,224 patients underwent isolated coronary artery bypass grafting. Of these 2477 (20\%) patients undergoing CABG had a previous acute myocardial infarction. The mortality in the patients who did not have MI was $1.07 \%(n=105)$. Compared to the non-MI cohort, patients who had a MI prior to undergoing a CABG had a significantly higher mortality 3.99\% (99 out of 2477; $p<0.001)$. 
Of the 2477 patients who underwent CABG after having a MI, 35 (1.4\%) patients were operated within 7 days of MI. The majority of the patients ( $n=1446 ; 58.3 \%)$ were operated between 1 week and 1 month after onset of symptoms. A large proportion of patients ( $n=998 ; 40.2 \%)$ were operated between 1 month and 3 months after a myocardial infarction. The mean age of the entire cohort was 57.85 \pm 8.80 years. The population consisted predominantly of male patients, who constituted $91.3 \%$ (2264) of the entire study group. The mean EuroSCORE of the entire study population was $4.93 \pm 2.18$.

The 3 groups were compared to assess if they had similar baseline and demographic characteristics (Table I). The group operated after 7 days but within 1 month were significantly older and had a significantly higher EuroSCORE $(p<0.001)$. Pre-operative anaemia was also more common in this group $(p=0.016)$. There was no difference in terms of previous neurological events $(p=0.554)$, presence of carotid artery disease $(p=0.555)$, and the prevalence of hypertension $(p=0.119)$, diabetes $(p=0.144)$, hypothyroidism $(p=0.53)$, chronic obstructive pulmonary disease $(p=0.079)$, or peripheral vascular disease (PVD) $(p=0.771)$ between the groups. The presence of impaired left ventricular function among patients was similar across the 3 groups $(p=0.072)$.
Operative details are summarized in Table II. Significantly more patients (11.4\%) in the group operated at 0-7 days were operated on an emergency basis $(p<0.001)$, and the presence of left main coronary artery disease was also significantly higher in this group $(p<0.001)$. Compared to other time periods, OPCAB as a strategy of revascularization was utilized in significantly fewer cases $(p<0.001)$. LIMA usage was similar across the 3 time periods $(p=0.262)$.

On bivariate analysis of outcome data (Table III) the patients operated within 7 days had significantly higher requirements for transfusion of blood or blood products. The group operated between 7 days and 1 month had significantly higher mortality compared to other time periods ( $p=0.003$ ) (Figure 1$)$. This group also had a significantly higher incidence of post-operative renal impairment $(p=0.003)$ and a longer hospital stay $(p<0.001)$. Respiratory complication $(p=0.744)$, adverse neurological events ( $p=0.421$ ), post-operative dysrhythmias $(p=0.184)$, and gastro-intestinal complications $(p=0.237)$ were similar across the groups.

On multivariate modelling and adjusting for other confounders, it was seen that the mortality following myocardial infarction was directly linked to the timing of the operation. To counter the effects of using arbitrary discrete

Table I. Baseline characteristics

\begin{tabular}{|c|c|c|c|c|}
\hline Parameter & $\begin{array}{l}0-7 \text { days } \\
(n=35)\end{array}$ & $\begin{array}{c}>7 \text { days }-1 \text { month } \\
(n=1444)\end{array}$ & $\begin{array}{c}>1-<3 \text { months } \\
(n=998)\end{array}$ & $P$-value \\
\hline Males & $30(85.7 \%)$ & 1326 (91.7\%) & 908 (91.3\%) & 0.407 \\
\hline Females & $5(14.3 \%)$ & $120(8.3 \%)$ & $215(8.7 \%)$ & \\
\hline Age & $57.54 \pm 8.16$ & $58.48 \pm 8.66$ & $56.95 \pm 8.94$ & $<0.001$ \\
\hline EuroSCORE & $4.74 \pm 1.95$ & $5.41 \pm 2.08$ & $4.24 \pm 2.15$ & $<0.001$ \\
\hline BMI & $23.14 \pm 3.39$ & $23.55 \pm 3.42$ & $23.5 \pm 3.45$ & 0.016 \\
\hline Hypertension & $33(94.3 \%)$ & $1172(81.1 \%)$ & $820(82.2 \%)$ & 0.119 \\
\hline History of smoking & $24(68.6 \%)$ & 1189 (82.2\%) & $845(84.7 \%)$ & 0.021 \\
\hline COPD & $2(5.7 \%)$ & 139 (9.6\%) & $71(7.1 \%)$ & 0.079 \\
\hline Diabetes & $14(40 \%)$ & $689(47.6 \%)$ & $438(43.9 \%)$ & 0.144 \\
\hline Hypothyroidism & $2(5.7 \%)$ & $64(4.4 \%)$ & $26(2.6 \%)$ & 0.053 \\
\hline Previous CVA & $1(2.9 \%)$ & $21(1.5 \%)$ & $11(1.1 \%)$ & 0.554 \\
\hline PVD & $2(5.7 \%)$ & 57 (3.9\%) & $36(3.6 \%)$ & 0.771 \\
\hline Carotid artery stenosis & $1(2.9 \%)$ & $112(7.7 \%)$ & $75(7.5 \%)$ & 0.555 \\
\hline Pre-op Hct $\leq 33 \%$ & $5(14.7 \%)$ & $216(15.3 \%)$ & $110(11.2 \%)$ & 0.016 \\
\hline$E F \leq 40 \%$ & $14(40 \%)$ & $580(40.1 \%)$ & 355 (35.6\%) & 0.072 \\
\hline
\end{tabular}

Table II. Operative data

\begin{tabular}{lccc} 
Parameter & $\begin{array}{c}0-7 \text { days } \\
(n=35)\end{array}$ & $\begin{array}{c}7 \text { days }-1 \text { month } \\
(n=1444)\end{array}$ & $\begin{array}{c}1-<3 \text { months } \\
(n=998)\end{array}$ \\
OPCAB & $29(82.9 \%)$ & $1404(97.2 \%)$ & $826(82.8 \%)$ \\
\hline LIMA usage & $28(80 \%)$ & $1159(80.3 \%)$ & $826(82.8 \%)$ \\
\hline Left main coronary artery disease & $7(20 \%)$ & $184(12.7 \%)$ & $85(8.5 \%)$ \\
\hline Emergency & $4(11.4 \%)$ & $16(1.1 \%)$ & 9.001 \\
\hline
\end{tabular}


Table III. Post-operative outcome

\begin{tabular}{|c|c|c|c|c|}
\hline Outcome & $\begin{array}{l}0-7 \text { days } \\
(n=35)\end{array}$ & $\begin{array}{c}>7 \text { days }-1 \text { month } \\
(n=1444)\end{array}$ & $\begin{array}{c}>1-<3 \text { months } \\
(n=998)\end{array}$ & $P$-value \\
\hline Transfusion & $30(85.7 \%)$ & $1184(82 \%)$ & 764 (76.6\%) & 0.004 \\
\hline Post-op arrhythmias & 4 (11.4\%) & $212(14.7 \%)$ & $123(12.3 \%)$ & 0.237 \\
\hline Gl complication & $0(0 \%)$ & $21(1.5 \%)$ & $7(0.7 \%)$ & 0.184 \\
\hline Respiratory complications & (17.1\%) & 75 (19\%) & $178(17.8 \%)$ & 0.744 \\
\hline Tracheostomy & $0(0 \%)$ & $34(2.4 \%)$ & $11(1.1 \%)$ & 0.054 \\
\hline Renal complications & $0(0 \%)$ & $91(6.3 \%)$ & $21(2.1 \%)$ & $<0.001$ \\
\hline Hospital stay & $7.4 \pm 1.6$ & $9.8 \pm 5.8$ & $9.4 \pm 4.6$ & 0.003 \\
\hline Mortality & $1(2.9 \%)$ & $74(5.1 \%)$ & $24(2.4 \%)$ & 0.003 \\
\hline
\end{tabular}

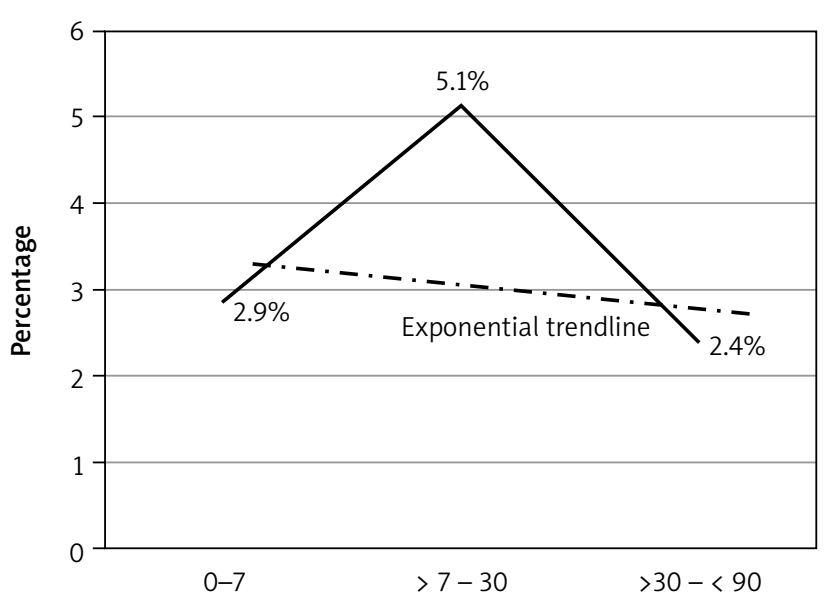

Figure 1. Temporal relationship between timing and outcome. The group operated after 7 days and within a month had significantly higher mortality compared to other time periods

time points we also used time as a continuous variable and examined its relationship with mortality. It was seen that the duration of time was independently and significantly associated with mortality and renal failure. The closer the duration between CABG and myocardial infarction, the higher the mortality (co-efficient $-0.517 ; p=0.019$; odds ratio $=0.596,95 \% \mathrm{Cl}: 0.388-0.917)$. A similar relationship existed between duration of time elapsed after myocardial infarction before CABG was undertaken and the incidence of post-operative renal impairment (Table IV).

\section{Discussion}

The main findings of our study were that mortality in patients with $\mathrm{MI}$ was significantly higher than in patients undergoing CABG, who did not have MI. The timing of the operation was an independent risk factor for mortality. The univariate analysis showed that the mortality risk within the first 7 days was $2.9 \%$, which increased significantly (5.9\%) when CABG was carried out between 1 week and 1 month, and then dropped to the lowest at $2.5 \%$ when CABG was carried out after 1 month. The adjusted multivariate analysis showed that CABG closer to the myocardial infarction had a higher mortality with the risk gradually decreasing as the duration between CABG and myocardial infarction increased.

A shorter gap between MI and CABG increases the occurrence of haemodynamic instability, left ventricle (LV) dysfunction, and arrhythmias in patients presenting for CABG. Moreover, continuation of anti-platelet agents and constraints towards optimal correction of deranged physiological parameters and an inability to modify cardiac morbidities further increase the risk of adverse outcomes. It has been suggested that following myocardial infarction there is increased oedema and fragility in myocardial tissue [4]. Thus, handling the myocardium early after an infarct may lead to further insult. Visualization of target vessel can be challenging in some cases. Moreover, successful revascularization of territories related to the infarct area is known to produce ischaemia-reperfusion injury [5].

Many studies carried out in the past support the findings of our study. The increase in mortality and morbidity

Table IV. Multivariate analysis to identify the independent effect of duration between MI and CABG on outcomes

\begin{tabular}{llllll} 
Parameter & Coefficient & P-value & Odds ratio & \multicolumn{2}{c}{$95 \% \mathrm{Cl}$ for odds ratio } \\
\cline { 4 - 6 } & & & & Lower & Upper \\
Transfusion & -0.171 & 0.099 & 0.843 & 0.688 & 1.032 \\
\hline Tracheostomy & -0.395 & 0.224 & 0.674 & 0.357 & 1.273 \\
\hline Renal & -0.731 & 0.001 & 0.482 & 0.315 & 0.735 \\
\hline DSWI & -0.282 & 0.746 & 0.754 & 0.137 & 4.159 \\
\hline Death & -0.517 & 0.019 & 0.596 & 0.388 & 0.917 \\
\hline
\end{tabular}


has been seen both where myocardial infarction was considered as a single identity $[4,11]$ as well as when it was considered separately as STEMI [12, 13] or non-STEMI [13].

The relationship between timing and mortality has been extensively studied. Thielmann et al. carried out a study in patients undergoing CABG after STEMI and demonstrated that the mortality was $10.8 \%$ for patients undergoing CABG within $6 \mathrm{~h}$ of onset of symptoms, rising to a peak of $23.8 \%$ if operated within 7-24 $\mathrm{h}$ after symptom onset, and declining again to $6.7 \%$ after $1-3$ days. The trend of decline in mortality continued and was $4.2 \%$ after $4-7$ days, and it finally reduced to $2.4 \%$ after $8-14$ days [12].

It has been shown by other researchers that CABG within 24 hours of a transmural (STEMI) myocardial infarct or 6 hours of a non-transmural (NSTEMI) infarct is an independent risk factor for mortality. However this premise has also been challenged by the findings of the ACTION (Acute Coronary Treatment and Intervention Outcomes Network) registry, which showed no difference in outcome between patients undergoing CABG within or after 48 hours of nonSTEMI. However, it should be noted that in the higher risk patients CABG was more often delayed [6].

Another study that specifically looked at the effect of duration between $\mathrm{MI}$ and CABG on both short- and longterm outcomes following CABG demonstrated that CABG soon after acute $\mathrm{MI}$ is associated with high operative mortality and morbidity and was also associated with worse long-term survival [4]. The authors concluded that this could be secondary to organ system dysfunction and blood transfusion, which were more common for short MI-toCABG intervals and perhaps negatively impacted survival. However, unlike our study, the authors of this study, after adjusting for confounders, did not find the MI-to-CABG interval to have a direct influence on operative mortality. This could have been due to a number of reasons, the most important being that their study included 1392 patients who had a CABG after MI within 90 days. The remaining patients had the CABG carried out after 90 days, when the risk is significantly reduced. However, in our study the total number of patients undergoing CABG after an MI was much larger at 2477 and perhaps had sufficient power to detect a difference after adjusting for confounders. So, while Ngaage et al. concluded that prognostic implications may have indirect associations with the timing of CABG after an MI, we were able to demonstrate that the length of time between $\mathrm{MI}$ and CABG has a direct influence on the operative mortality as well as renal impairment [4].

In our study univariate analysis showed an interesting phenomenon where the morality was lower within the first week and then increased until 1 month and subsequently decreased again. Similar findings have been reported by other studies. It has been shown that the mortality was lower in the initial phase, highest between 2-6 weeks, and then reduced again after 6 weeks [14]. Another study in keeping with our findings showed that the mortality in the first week was lower than the mortality at 1-3 weeks, which again reduced after 3 weeks [15].
While there is overwhelming data suggesting that CABG after myocardial infarction carries higher risk, the ideal duration one should wait after an MI before CABG is undertaken remains controversial.

Attempts to decide a definite cut-off have been difficult and studies have attempted to create several cut-off time points. Based on these arbitrary cut-off points different studies have tried to create different cohorts and have arrived at different conclusions. The cut-off time points at which these various comparisons have been made are 1 day [13], 2 days [6], 3 days [8], 7 days [13], 10 days [16], 14 days [12], 3 weeks [17], and 6 weeks [14]. While there is a general acceptance that a longer gap between $\mathrm{MI}$ and CABG reduces the risk, it appears that it is difficult if not impossible to come to a consensus over the ideal cut-off time for CABG. Perhaps time as an independent variable is not robust enough to predict the appropriate timing of CABG in isolation. This is also reflected in the guidelines provided by the European Society of Cardiology (ESC) and the American Heart Association/American College of Cardiology (ACC/AHA). The ACC/AHA 2004 guidelines update acknowledges that the "risk of CABG in patients early after non-STEMI and during acute $\mathrm{MI}$ is increased several fold relative to patients with stable angina, although the risk is not necessarily higher than that of medical therapy in these patients". In cases of STEMI it has been mentioned that CABG mortality is elevated for the first 3-7 days after infarction in patients who have had a STEMI, and the benefit of revascularization in this group must be balanced against the increased risk [18].

The more recent recommendations from the European Society of Cardiology (ESC) suggest that in the absence of mechanical complications the role of CABG in STEMI is very limited [19]. In the context of NSTEMI it has been suggested that in the absence of randomized data, optimal timing should be determined individually by the heart team based on the guidance provided [20]. These guidelines take cognizance of the fact that there is significant inter-group heterogeneity between time-defined groups. For instance, patients presenting within 7 days of AMI may include patients with differing haemodynamic stability and a varying degree of critical coronary anatomy, and they may or may not have mechanical complications. Thus, a time-bound recommendation may not be applicable to the whole group and would be highly erroneous. In keeping with the guidelines and the findings of our study it appears that while time does influence mortality, it might be more prudent to move away from a time-based intervention to a "heartteam" based intervention, especially in the more complex cohort of patients in whom early CABG is contemplated.

Our study was retrospective in nature and has some important limitations. An important limitation of our study was the small number of patients who were operated within 7 days. This could be a reflection in part of a selection bias. The small numbers also make it difficult to draw meaningful conclusions from the outcome is this group. One of the other important limitations of our study is that we have 
used acute myocardial infarction to encompass both STEMI and non-STEMI. Perhaps examining these 2 entities separately would be clinically more relevant. However, our data collection precedes the introduction of this classification in our database and hence we were unable to separate these 2 clinical entities. Moreover, the number of patients who required CABG surgery in the acute phase of STEMI is small, and selection bias cannot be ruled out. However, the same definition was applied to both the groups and it is unlikely to have prejudiced the findings of our study.

Despite the limitations, our study confirms that the mortality after $\mathrm{MI}$ is higher than that in patients who did not have an $\mathrm{MI}$ prior to undergoing CABG. It is clear that the longer the duration between $\mathrm{MI}$ and $\mathrm{CABG}$, the lower is the mortality risk; it is however difficult to decide on an exact cut-off time frame. Each case has to be individualized, and the problems of waiting (recurrence of ischaemic insult and resource utilization) have to be balanced against the increased risk of early CABG. The influence of timing on outcome should be considered but should not be the solitary criterion in making a decision. Perhaps a heart time approach in the more complex cases would be a more prudent approach.

\section{Disclosure}

The authors report no conflict of interest.

\section{References}

1. Bana A, Yadava OP, Ghadiok R, Selot N. Myocardial revascularisation after acute myocardial infarction. Int J Cardiol 1999; 69: 209-216.

2. Louagie YA, Jamart J, Buche M, Eucher PM, Schoevaerdts D, Collard E. Operation for unstable angina pectoris: factors influencing adverse in-hospital outcome. Ann Thorac Surg 1995; 59: 1141-1149.

3. Caceres $M$, Weiman DS. Optimal timing of coronary artery bypass grafting in acute myocardial infarction. Ann Thorac Surg 2013; 95: 365-372.

4. Ngaage DL, Sogliani F, Tang A. Early and late prognostic implications of coronary artery bypass timing after myocardial infarction. Eur J Cardiothorac Surg 2013; 43: 549-554.

5. Bell RM, Yellon DM. There is more to life than revascularization: therapeutic targeting of myocardial ischemia/reperfusion injury. Cardiovasc Ther 2011; 29: e67-e79.

6. Parikh SV, de Lemos JA, Jessen ME, Brilakis ES, Ohman EM, Chen AY, Wang TY, Peterson ED, Roe MT, Holper EM. Timing of in-hospital coronary artery bypass graft surgery for non-ST-segment elevation myocardial infarction patients results from the National Cardiovascular Data Registry ACTION Registry-GWTG(Acute Coronary Treatment and Intervention Outcomes Network Registry-Get With The Guidelines). JACC Cardiovasc Interv 2010; 3: 419-427.
7. Deeik RK, Schmitt TM, Ihrig TG, Sugimoto JT. Appropriate timing of elective coronary artery bypass graft surgery following acute myocardial infarction. Am J Surg 1998; 176: 581-585.

8. Weiss ES, Chang DD, Joyce DL, Nwakanma LU, Yuh DD. Optimal timing of coronary artery bypass after acute myocardial infarction: a review of California discharge data. J Thorac Cardiovasc Surg 2008; 135: 503-511.

9. Tu JV, Sykora K, Naylor CD. Assessing the outcomes of coronary artery bypass graft surgery (how many risk factors are enough? Steering Committee of the Cardiac Care Network of Ontario). J Am Coll Cardiol 1997; 30: 1317-1323.

10. Davierwala PM, Verevkin A, Leontyev S, Misfeld M, Borger MA, Mohr FW. Does timing of coronary artery bypass surgery affect early and long-term outcomes in patients with non-ST-segment-elevation myocardial infarction? Circulation 2015; 132: 731-740.

11. Zaroff JG, di Tommaso DG, Barron HV. A risk model derived from the National Registry of Myocardial Infarction 2 database for predicting mortality after coronary artery bypass grafting during acute myocardial infarction. Am J Cardiol 2002; 90: 1-4.

12. Thielmann M, Neuhäuser M, Marr A, Herold U, Kamler M, Massoudy P, Jakob $\mathrm{H}$. Predictors and outcomes of coronary artery bypass grafting in ST elevation myocardial infarction. AnnThorac Surg 2007; 84: 17-24.

13. Lee DC, Oz MC, Weinberg AD, Lin SX, Ting W. Optimal timing of revascularization: transmural versus nontransmural acute myocardial infarction. Ann Thorac Surg 2001; 71: 1197-1202.

14. Creswell LL, Moulton MJ, Cox JL, Rosenbloom M. Revascularization after acute myocardial infarction. Ann Thorac Surg 1995; 60: 19-26.

15. Nichols EL, McCullough JN, Ross CS, Kramer RS, Westbrook BM, Klemperer JD, Leavitt BJ, Brown JR, Olmstead E, Hernandez F, Sardella GL, Frumiento C, Malenka D, DiScipio A.; Northern New England Cardiovascular Disease Study Group. Optimal timing from myocardial infarction to coronary artery bypass grafting on hospital mortality. Ann Thorac Surg 2017; 103: 162-171.

16. Assmann A, Boeken U, Akhyari P, Lichtenberg A. Appropriate timing of coronary artery bypass grafting after acute myocardial infarction. Thorac Cardiovasc Surg 2012; 60: 446-451.

17. Wang R, Cheng N, Xiao CS, Wu Y, Sai XY, Gong ZY, Wang Y, Gao CQ. Optimal timing of surgical revascularization for myocardial infarction and left ventricular dysfunction. Chin Med J (Engl) 2017; 130: 392-397.

18. Eagle KA, Guyton RA, Davidoff R, Edwards FH, Ewy GA, Gardner TJ, Hart JC, Herrmann HC, Hillis LD, Hutter Jr AM, Lytle BW, Marlow RA, Nugent WC, Orszulak TA; American College of Cardiology; American Heart Association. ACC/ AHA 2004 guideline update for coronary artery bypass graft surgery: a report of the American College of Cardiology/American Heart Association Task Force on Practice Guidelines. Circulation 2004; 110: e340-e437.

19. Steg PG, James SK, Atar D, Badano LP, Blömstrom-Lundqvist C, Borger MA, Di Mario C, Dickstein K, Ducrocq G, Fernandez-Aviles F, Gershlick AH, Giannuzzi P, Halvorsen S, Huber K, Juni P, Kastrati A, Knuuti J, Lenzen MJ, Mahaffey KW, Valgimigli M, van 't Hof A, Widimsky P, Zahger D. ESC Guidelines for the_management of acute myocardial infarction in patients presenting with ST-segment elevation. Eur Heart J 2012; 33: 2569-2619.

20. Roffi M, Patrono C, Collet JP, Mueller C, Valgimigli M, Andreotti F, Bax JJ, Borger MA, Brotons C, Chew DP, Gencer B, Hasenfuss G, Kjeldsen K, Lancellotti P, Landmesser U, Mehilli J, Mukherjee D, Storey RF, Windecker S, ESC Scientific Document Group. 2015 ESC Guidelines for the management of acute coronary syndromes in patients presenting without persistent ST-segment elevation: Task Force for the Management of Acute Coronary Syndromes in Patients Presenting without Persistent ST-Segment Elevation of the European Society of Cardiology (ESC). Eur Heart J 2016; 37: 267-315. 